\section{Thymidine Phosphorylase Inhibitors with a Homophthalimide Skeleton}

\author{
Tetsuya KitA, Hiroyasu TAKAHASHI, and \\ Yuichi НаSHIMOTO*
}

Institute of Molecular and Cellular Biosciences, University of Tokyo, 1-1-1 Yayoi, Bunkyo-ku, Tokyo 113-0032, Japan.

Received February 5, 2001; accepted May 18, 2001

Several $N$-phenylhomophthalimide derivatives were prepared and their inhibitory activity on thymidine phosphorylase/ platelet-derived endothelial cell growth factor (TP/PD-ECGF) was assessed. Among them, 2-(2,6-diethylphenyl)-7-nitro-1,2,3,4tetrahydroisoquinoline-1,3-dione (9) was found to be a more potent inhibitor than the classical inhibitor, 5-nitrouracil (1). Lineweaver-Burk plot analysis indicated that 9 shows mixedtype competitive inhibition of TP/PD-ECGF, while 1 is a competitive inhibitor.

Key words homophthalimide; thymidine phosphorylase; inhibitor; platelet-derived endothelial cell growth factor

Thymidine phosphorylase (TP: EC 2.4.2.4) is an enzyme which catalyzes the reversible phosphorolytic degradation of thymidine to thymine and 2-deoxyribose-1-phosphate, and is considered to be essential in the thymidine salvage pathway. ${ }^{1)}$ This enzyme also recognizes other pyrimidine nucleoside derivatives with antitumor/antivirus activities, including 5-fluoro-2'-deoxyuridine and 5-trifluoromethyl-2'-deoxyuridine. The forward reaction can be regarded as a deactivation of antitumor/antiviral agents. ${ }^{1)}$

Recently, TP was shown to be identical to platelet-derived endothelial cell growth factor (PD-ECGF), an important factor involved in angiogenesis. ${ }^{2,3)}$ It has also been reported that TP/PD-ECGF is expressed in abnormally high levels in some human tumors. ${ }^{1-3)}$ Therefore, inhibitors of TP/PDECGF may elicit beneficial biological effects by acting as antiangiogenic agents and/or subsidiary agents enhancing the bioavailability of deoxynucleoside-type antitumor/antiviral agents. However, only a few inhibitors of TP/PD-ECGF have been reported up to now, and all of them are pyrimidine or purine derivatives, e.g., 5-nitrouracil (1, Fig. 1) and 7deazaxanthine-5-chloro-6-[(2-iminopyrrolidin-1-yl)methyl]uracil. $^{4-7)}$

We have been engaged in structural development studies of thalidomide [ $N(\alpha)$-phthalimide glutarimide], which possesses pleiotropic activities including antiangiogenic activity and tumor necrosis factor (TNF)- $\alpha$ production-regulating activity. ${ }^{8-10)}$ Previously we reported potent novel antiangiogenic agents with a phthalimide/homophthalimide skeleton derived from thalidomide. ${ }^{11)}$ The structure-activity relationship studies indicated that the potency of the antiangiogenic effects elicited by the phthalimide/homophthalimide derivatives is not related to inhibitory activity on TNF- $\alpha$ production, ${ }^{8-10)}$ aminopeptidases ${ }^{11,12)}$ dipeptidylpeptidase type $\mathrm{IV}^{13)}$ or androgen receptor ${ }^{8,14)}$ (all of which are known to induce or enhance angiogenesis). So, we suspected that TP/PD-ECGF might be a target molecule of our phthalimide/homophthalimide-type antiangiogenic agents. Therefore, several homophthalimide derivatives were prepared and their inhibitory activity on TP/PD-ECGF was assessed.
Homophthalimide derivatives $(\mathbf{2}, \mathbf{4}, \mathbf{6}, \mathbf{7}, \mathbf{9}-\mathbf{1 2}$, Fig. 1) were prepared by condensation of substituted or non-substituted homophthalic anhydride with appropriate amines by the usual synthetic method in good yields. Tricarbonyl derivatives $(\mathbf{3}, \mathbf{5}$, Fig. 1) were obtained by oxidation of the corresponding homophthalimides $\left(\mathbf{2}, \mathbf{4}\right.$, respectively). ${ }^{15)}$ Oxidation of the latter compound (4) occurs quite easily, and mere dissolution of $\mathbf{4}$ in methanol under normal sunlight at room temperature followed by immediate work-up yielded $\mathbf{5}$ quantitatively, as reported previously. ${ }^{16)}$ Structures were confirmed by spectroscopic data (NMR and Mass) and all the compounds gave appropriate analytical values.

The inhibitory effect of the compounds on TP/PD-ECGF was assessed by using the spectroscopic method described by Yoshimura et al. ${ }^{17)}$ Test compounds were dissolved in dimethylsulfoxide at the concentration of more than $10 \mathrm{~mm}$ as stock solutions, and used after dilution to appropriate concentrations with a reaction buffer (vide infra). Briefly, TP/PD-ECGF (Sigma) was incubated with or without various concentrations of test compounds in $50 \mathrm{~mm} 2$-morpholinoethanesulfonic acid (MES) buffer $(\mathrm{pH} 5.6)$ at $37^{\circ} \mathrm{C}$ for $5 \mathrm{~min}$. Then the substrate (thymidine) was added at the final concentration of $2 \mathrm{~mm}$, and the mixture was incubated at $37^{\circ} \mathrm{C}$ for $30 \mathrm{~min}$. The reaction was stopped by adding aqueous sodium hydroxide, and the amount of formed thymine was calculated from the absorbance at $300 \mathrm{~nm}$. As a positive control compound, the classical inhibitor 5-nitrouracil (1) was adopted. Although the obtained $\mathrm{IC}_{50}$ values deviated from experiment to experiment, the data were basically reproducible. The experiments were performed at least in duplicate, and the mean values are taken. The order of TP/PDECGF-inhibition potency of the compounds assessed at the same time was always the same. Therefore, the typical set of data obtained by the experiment performed at the same time

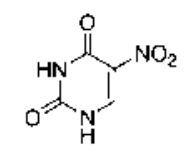

;<smiles>CCc1cccc(CC)c1N1C(=O)Cc2ccccc2C1=O</smiles>

$\mathbf{q}$<smiles>O=C1Cc2ccccc2C(=O)N1C1=C(Cl)CCC=C1Cl</smiles>

7

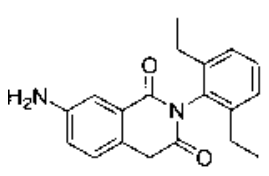

10<smiles>O=C1Cc2ccccc2C(=O)N1c1ccccc1</smiles>

2<smiles>CCc1ccccc1N1C(=O)C(=O)c2ccccc2C1=O</smiles>

5<smiles>O=C1c2ccccc2C(=O)N1c1ccccc1</smiles>

a

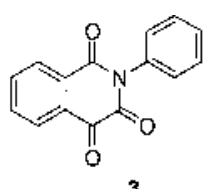

3
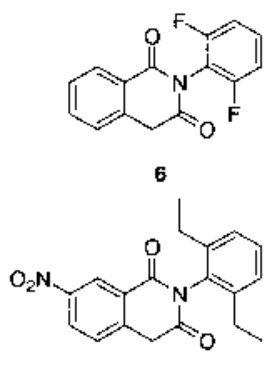

9

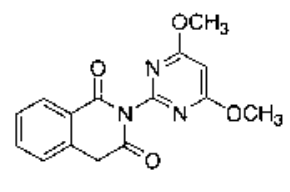

11

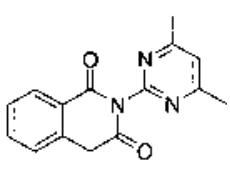

12
Fig. 1. Structures of 5-Nitrouracil, Homophthalimide Derivatives and Related Compounds 
Table 1. Inhibition of TP/PD-ECGF by Homophthalimide Derivatives

\begin{tabular}{rcr}
\hline \hline Compound & $\mathrm{mp}\left({ }^{\circ} \mathrm{C}\right)$ & $\mathrm{IC}_{50}(\mu \mathrm{M})$ \\
\hline $\mathbf{1}$ & - & 414 \\
$\mathbf{2}$ & 233 & 452 \\
$\mathbf{3}$ & $223-224$ & $>500$ \\
$\mathbf{4}$ & $108-110$ & 460 \\
$\mathbf{5}$ & $163-165$ & $>500$ \\
$\mathbf{6}$ & $209-210$ & $>500$ \\
$\mathbf{7}$ & $\left.\mathrm{Oii}^{a}\right)$ & 367 \\
$\mathbf{8}$ & $209-211$ & $>500$ \\
$\mathbf{9}$ & $170-171$ & 246 \\
$\mathbf{1 0}$ & $153-155$ & 408 \\
$\mathbf{1 1}$ & $224-226$ & $>500$ \\
$\mathbf{1 2}$ & $251-253$ & 413 \\
\hline
\end{tabular}

a) bp $250^{\circ} \mathrm{C}(2.0 \mathrm{mmHg})$.

are presented (Table 1).

As shown in Table 1, some of the homophthalimide derivatives showed stronger inhibitory activity than 5-nitrouracil (1: $\left.\mathrm{IC}_{50}=414 \mu \mathrm{M}\right)$. The simple $N$-phenylhomophthalimide, 2, is moderately active $\left(\mathrm{IC}_{50}=452 \mu \mathrm{M}\right)$, while the corresponding phthalimide analog $(\mathbf{8})$ is inactive $\left(\mathrm{IC}_{50}>500 \mu \mathrm{M}\right)$. Oxidation of the active compounds, 2 and $\mathbf{4}$, at the 4-position, i.e., tricarbonyl derivatives $(\mathbf{3}, \mathbf{5}$, respectively), also diminished the activity. This suggests that a homophthalimide skeleton is necessary for the inhibitory effect. Exchange of the substituted/non-substituted phenyl group at the 2-position for heteroaromatics $(\mathbf{1 1}, \mathbf{1 2})$ diminished or did not affect the activity.

Although the non-substituted derivative (2) and the 2,6diethyl derivative (4) showed comparable activities $\left(\mathrm{IC}_{50}=\right.$ $452-460 \mu \mathrm{M})$, substitution at positions 2 and 6 of the $N$ phenyl ring with halogen atoms altered the activity; i.e., 2,6difluoronation caused disappearance of the activity (6: $\left.\mathrm{IC}_{50}>500 \mu \mathrm{M}\right)$, and 2,6-dichlorination resulted in enhancement of the activity $\left(7: \mathrm{IC}_{50}=367 \mu \mathrm{M}\right)$. Our previous studies showed that compounds $\mathbf{2}$ and $\mathbf{7}$ exhibit cell toxicity at high concentrations $(>300 \mu \mathrm{M})$, while $\mathbf{4}$ is completely non-toxic at these concentrations. ${ }^{11-13,15)}$ Therefore, we chose $\mathbf{4}$ as a mother compound for further development.

The structure-activity relationship studies of classical pyrimidine derivatives including 5-nitrouracil (1) reported by Niedzwicki et al. ${ }^{18)}$ suggested that the nitro group plays a critical role for potent activity. Therefore, we introduced a nitro and an amino group at the putatively corresponding site, i.e., position 7, of compound 4. As expected, the introduction of an electron-withdrawing nitro group at the 7-position (9) caused potent enhancement of the activity $\left(\mathrm{IC}_{50}=\right.$ $246 \mu \mathrm{M})$ and afforded in an inhibitor which is much more potent than 5-nitrouracil (1). Introduction of an electron-donating amino group at the same position (10) also caused enhancement of the activity $\left(\mathrm{IC}_{50}=408 \mu \mathrm{M}\right)$, though its efficacy was far less than that of a nitro group introduction.

Though the activity-enhancing effect of a nitro group in a homophthalimide derivative (9) is similar to that in the wellknown pyrimidine derivatives, including 5-nitrouracil (1), the effect of an amino group in our homophthalimide derivative (10) is not the same as in pyrimidine derivatives. ${ }^{17)}$ This might suggest a difference of inhibitory mechanism between the active pyrimidine analogs and our homophthalimide derivatives.

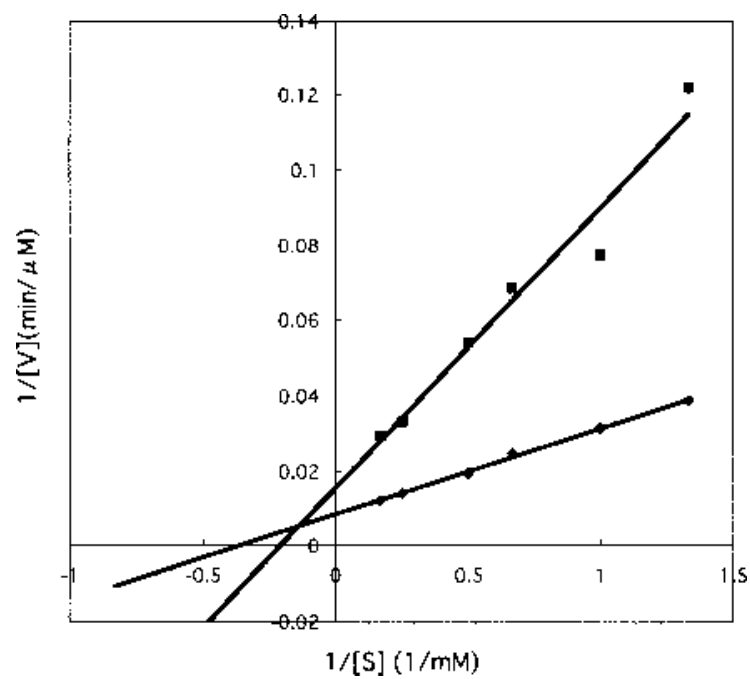

Fig. 2. Lineweaver-Burk Plot Analysis of TP/PD-ECGF Inhibition by Compound 9

TP/PD-ECGF was incubated with the substrate in the presence $(\boldsymbol{\square})$ or absence $(\bullet)$ of 9.

5-Nitrouracil inhibits TP/PD-ECGF in a competitive manner. ${ }^{18)}$ Other pyrimidine derivatives including 5-bromo-, 5fluoro-, and 5-aminouracil also inhibit TP/PD-ECGF in a competitive manner. To determine the inhibition mode of compound 9, Lineweaver-Burk plot analysis was performed (Fig. 2). The analyses was repeated more than three times, and all the analysis indicated that compound 9 inhibits TP/PD-ECGF in a mixed-type competitive mode, as shown in Fig. 2. This type of TP/PD-ECGF inhibition is rare; so far, mixed type inhibition has been reported only for 6-benzyl-2thiouracil, ${ }^{19)}$ as far as we know. Although we have no information about the mechanism yet, one possible explanation of the mixed-type inhibition by compound 9 might be the existence of at least two binding sites for 9 on TP/PD-ECGF, with one being the substrate binding site.

Further structural development, structure-activity relationship studies, and elucidation of the binding site(s) of 9 on TP/PD-ECGF are in progress. Our inhibitors, some of which are more potent than 5-nitrouracil (1), should be superior lead compounds for novel type(s) of TP/PD-ECGF inhibitors.

Acknowledgements The work described in this paper was partially supported by funds for the Promotion of Fundamental Studies in Health Science from the Organization for Pharmaceutical Safety Research, and Grant-in-Aid from the Ministry of Education, Science, Sports, and Culture of Japan.

\section{REFERENCES}

1) Desgranges C., Razaka G., Rabaud M., Bricaud H., Balzarini J., De Clercq E., Biochem. Pharmacol., 32, 3583-3590 (1983).

2) Moghaddam A., Zang H. T., Fan T. P., Hu D. E., Lees V. C., Turley H., Fox S. B., Gattar K. C., Harris A. L., Bicknell R., Proc. Natl. Acad. Sci. U.S.A., 92, 998-1002 (1995).

3) Miyadera K., Sumizawa T., Haraguchi M., Yoshida H., Konstanty W., Yamada Y., Akiyama S., Cancer Res., 55, 1687-1690 (1995).

4) Esteban-Gamboa A., Balzarini J., Esnouf R., De Clercq E., Camarasa M. J., Perez-Perez M. J., J. Med. Chem., 43, 971-983 (2000).

5) Focher F., Ubiali D., Pregnolato M., Zhi C., Gambino J., Wright G. E., Spadari S., J. Med. Chem., 43, 2601-2607 (2000). 
6) Balzarini J., Gamboa A. E., Esnouf R., Liekens S., Neyts J., De Clercq E., Camarasa M. J., Perez-Perez M. J., FEBS Lett., 438, 91-95 (1998).

7) Fukushima M., Suzuki N., Emura T., Yano S., Kazuo H., Tada Y., Yamada Y., Asao T., Biochem. Pharmacol., 59, 1227-1236 (2000).

8) Hashimoto Y., Curr. Med. Chem., 5, 163-178 (1998).

9) Miyachi H., Azuma A., Ogasawara A., Uchimura E., Watanabe N., Kobayashi Y., Kato F., Kato M., Hashimoto Y., J. Med. Chem., 40, 2858-2865 (1997).

10) Miyachi H., Ogasawara A., Azuma A., Hashimoto Y., Bioorg. Med. Chem., 5, 2095-2102 (1997).

11) Shimazawa R., Takayama H., Fujimoto Y., Komoda M., Dodo K., Yamasaki R., Shirai R., Koiso Y., Miyata K., Kato F., Kato M., Miyachi H., Hashimoto Y., J. Enzyme Inhibition, 14, 259-275 (1999).

12) Miyachi H., Kato M., Kato F., Hashimoto Y., J. Med. Chem., 41, 263-265 (1998).
13) Shimazawa R., Takayama H., Kato F., Kato M., Hashimoto Y., Bioorg. Med. Chem. Lett., 9, 559-562 (1999).

14) Miyachi H., Azuma A., Kitamoto T., Hayashi K., Kato S., Koga M., Sato B., Hashimoto Y., Bioorg. Med. Chem. Lett., 7, 1483-1488 (1997).

15) Komoda M., Kakuta H., Takahashi H., Fujimoto Y., Kadoya S., Kato F., Hashimoto Y., Bioorg. Med. Chem., 9, 121-131 (2001).

16) Takahashi H., Komoda M., Kakuta H., Hashimoto Y., Yakugaku Zasshi, 120, 909-921 (2000).

17) Yoshimura A., Kuwazuru Y., Furukawa T., Yoshida H., Yamada K., Akiyama S., Biochim. Biophys. Acta, 1034, 107-113 (1990).

18) Niedzwicki J. G., el Kouni M. H., Chu S. H., Cha S., Biochem. Pharmacol., 32, 399-415 (1983).

19) Miszczak-Zaborska E., Wozniak K., Z. Naturforsh., 52(C), 670-675 (1997). 